\title{
RESPONSABILIDADE DO ESTADO POR DANO MORAL
}

O conceito consagrado no plano do direito privado determina a obrigação de indenizar o dano causado ao patrimônio de outrem por ação ou omissão própria. A ninguém é dado lesar bem ou direito alheio (neminem laedere). Presente o dano injustamente produzido, o nexo causal faz nascer a obrigação de restaurar o equilibrio rompido pela conduta lesiva.

Vinculada originariamente à culpa do agente, a responsabilidade civil adquiriu, sobretudo por influência de acidentes no trabalho, sentido amplo em que a noção do risco assumido basta para gerar o dever reparatório, independentemente do elemento de vontade do autor.

Entre nós, se o Código Civil de 1916 manteve-se fiel ao modelo clássico da responsabilidade por culpa (art. 159), a doutrina e a jurisprudência progressivamente avançaram na construção da responsabilidade objetiva, a que leis especiais têm dado guarida.

No altiplano constitucional, ao princípio da solidariedade com o funcionário faltoso, impresso nas Cartas anteriores, a Constituição de 1946 substituiu a norma de responsabilidade direta e primária do Estado por dano causado a terceiros na prática administrativa.

Dita o artigo 194 desta quarta Magna Lei republicana que "as pessoas jurídicas de direito público interno são civilmente responsáveis pelos danos que os seus funcionários, nessa qualidade, causem a terceiros". E, somente quando tivessem agido com culpa se tornava cabível ação regressiva, conforme o respectivo parágrafo único.

Preceito idêntico reaparece no sistema constitucional imediato, como previsto no art. 105 da Constituição de 1967 (art. 107 da Emenda Constitucional no 1, de 1969).

$\mathrm{Na}$ vigência destes textos, dividiram-se os intérpretes sobre o exato entendimento do comando constitucional, como procuramos documentar em estudo a ele contemporâneo (Tendências atuais sobre a responsabilidade civil do Estado, in Revista de Direito Administrativo, vol. 55, p. 262/s.). Respeitável corrente doutrinária encontrou na sobriedade da redação a acolhida da teoria do risco, em substituição ao princípio de necessário elemento subjetivo de culpa ou dolo como fato gerador de responsabilidade do poder público. Outra linha conservadora reputava neutra a diç̧ão cons- 
titucional, a importar na subsistência da norma ordinária de responsabilidade subjetiva.

Por influência especial do direito francês, elaborado na jurisprudência do Conselho de Estado, firmou-se, porém, dominantemente na exegese dos tribunais nacionais a noção de que o impacto da atividade administrativa sobre os bens e direitos privados impunha ao Estado o dever de responder objetivamente pelo risco do serviço.

A atual Constituição de 1988 manteve-se na esteira do comando inaugurado em 1946.

Proclama o $\$ 6^{\circ}$ do art. 37 que "as pessoas jurídicas de direito público e as de direito privado prestadoras de serviço público responderão pelos danos que seus agentes, nessa qualidade, causarem a tereeiros, assegurado o direito de regresso contra o responsável nos casos de dolo ou culpa".

Apenas tornou-se explícita a amplitude da norma para alcançar as pessoas privadas a que for delegada a prestação de serviço público. E permaneceu excluída a responsabilidade estatal se a conduta do funcionário operou abusivamente, ou seja, fora do ambito de suas funções.

Comprovada, no entanto, a premissa do exercicio regular da função, assume o Estado objetivamente a responsabilidade pelo risco administrativo, reservando-se o requisito de subjetividade tão-somente para a eventual ação regressiva contra o funcionário responsável.

A responsabilidade civil pressupde a existência de prejufzo a ser ressarcido pelo lesante. É a violação do bem ou direito que gera, em contrapartida, a obrigação de recompor a situação preexistente de modo a que se restaure o estado de equilibrio subvertido.

A relação jurídica se constitui, assim, pela integração de quatro elementos essenciais: a pessoa do lesado, titular do direito ofendido: a pessoa do lesante, autor do ato ou omissão; a consumação do dano e, como requisito necessário, o nexo de causalidade entre o dano e o fato gerador.

A responsabilidade civil se apresenta em duas modalidades básicas: a responsabilidade contratual a responsabilidade extracontratual.

Na primeira categoria, a reparação do dano é fruto do acordo de vontades em que se estipula a prestação que visa a restaurar a harmonia no objeto do pacto bilateral.

A obrigação de indenizar pode, contudo, prescindir de manifestação de consentimento. A culpa ou dolo na prática do ato lesivo é suficiente para dar origem ao dever jurídico de sanar o prejuízo atual e certo, gerado pela conduta do lesante. A responsabilidade extracontratual deriva do princípio de integridade dos direitos postos em confronto.

Mais ainda se aperfeiçon o dever de compor o prejufzo quando se admite que o simples exercício da atividade, ou a inércia em agir, importa na assunçlo do riseo do possivel resultado danoso. 
Em princípio, concebe-se o dano material, quantificável na proporção do prejufzo de modo a recompor, pela via indenizatória, o valor integral do bem ou direito lesado.

Não fiea, porém, na reparação do dano material a obrigação de indenizar.

A segurança jurfdiea vai além dos valores materiais que integram o patrimônio.

Por mais respeitáveis que sejam os valores economicos, não são menos relevantes para o homem os valores de seu patrimônio ideal, insuscetfveis de medida financeira, mas essenciais ao equilf́brio de sua personalidade.

A honra, a reputação, a dignidade, a fama e a notoriedade o conceito social ou profissional, a convivência familiar, sĩo tão importantes essenciais ao homem como os hens da fortuna, se nào mais valiosos.

É mister. assim, que a ordem jurfelica não se limite a proteger a posse ou domínio de bens físicos ou a fruiçiono de direitos de propriedade, mas igualmente preserve a imutabilidade de direitos imateriais.

A lesto a estes valores morais da pessoa humana é. conceitualmente um prejufzo a que o direito nà pode ficar indiferente.

WILSON MELL_O DA SILVA, em obra clássica (O dano moral e sua reparação - 1" edição, 1955) mostrou a presença, ainda que sumária, do dano moral nos Códigos de Manu e de Hamurabi, como na Grécia antiga e no direito romano.

No Livro VIII do Código de Manu cabia impor pesada multa aquele que desse em casamento "uma donzela com defeitos" e a condenaçăo injusta de um inocente impunha aos jufzes, na revisão do processo, multa pecuniária de mil panas.

$\mathrm{Na}$ Odisséia de Homero, surpreendendo a esposa Afrodite em flagrante de adultério. o marido coxo é favorecido, no julgamento dos deuses, com o benefício de pesada multa.

A reparação de prejufzos morais atravessa, com variações de Ambito e intensidade, desde o direito romano ao direito moderno, tanto ao direito canónico como ao direito comum.

III

O tema dos direitos morais não se eireunscreve, entre nós, à previsão no direito privado, que é o seu campo por excelência.

A Constituiçâo brasileira de 1988 incorpora preceitos sobre a matéria, compondo o que a doutrina italiana se chamou de direito civil constitucional.

No art. $5^{\circ}-$ em que se arrolam os direitos e garantias fundamentais - assegura-se, a par do direito de resposta proporcional ao agravo, a indenização por dano material e moral.

$E$, adiante, $\theta$ item $X$ do mesmo preceito afirma invioláveis a intimidade, a vida privada, a honra e a imagem das pessoas e a elas assegura o direito de indenizaçato por dano material e moral.

A proteçlo constitucional a imagem - pondera MIGUEL REALE = "não se refere, evidentemente, ao aspecto físico da pessoa, mas à sua dimensâo ética perante 
a coletividade, implicando necessariamente um dano moral" (Temas de Direito Positivo - $1992-$ p. 22).

Também, o item LXXV consagra a indenização por erro judiciário como pelo excesso na execução da pena.

O princípio da responsabilidade por dano moral transita na legislação ordinária tanto no plano privado como no campo dos serviços públicos.

O texto original do Código Brasileiro de Telecomunicações (Lei n ${ }^{\circ} 4.117$, de 27 de agosto de 1962, alterada por leis posteriores) especificou, em seu artigo 81, que, independentemente da ação penal, o ofendido por calúnia, difamação ou injúria cometida por meio de radiodifusão poderá demandar no Juízo Cível à reparação do dano moral, respondendo solidariamente por este o ofensor e a concessionária ou permissionária, quando culpada por ação ou omissão, assim como quem quer que, favorecido pelo crime, haja de qualquer modo contribuído para ele.

Mais adiante a mesma lei estabelece, no artigo 84 , que na estimação do dano moral o juiz terá em conta, notadamente a posição social ou política do ofendido, a situação econômica do ofensor, a intensidade do ânimo de ofender, a gravidade e repercussão da ofensa.

E o artigo 87 dilata a construção legal, afirmando que a reparação dos danos morais será aplicável, no que couber, ao ilícito contra a honra praticado por meio da imprensa.

A Lei $n^{\circ} 5.250$, de 6 de fevereiro de 1967 , reconhece, no art. $4^{\circ}$, a obrigação de reparar o dano moral aquele que, no exercício da liberdade de manifestação do pensamento e da informação, agindo com dolo ou culpa, violar direito ou causar prejuízo a outrem. Nem mesmo a prova da verdade excluirá a responsabilidade civil se o fato imputado, embora verdadeiro, disser respeito à vida privada do ofendido e a divulgação não houver sido motivada em razão de interesse público (art. $4^{\circ}, \S 1^{\circ}$ ).

O direito eleitoral igualmente consagra o princípio de reparação do dano moral. A Lei $n^{\circ} 4.737$, de 15 de julho de 1965 , ao cuidar da propaganda partidária, estabelece, no art. $243, \S 1^{\circ}$, que o ofendido por calúnia, difamação ou injúria, independentemente da ação penal competente, poderá demandar, no Juízo Cível, a reparação do dano moral, respondendo por este o ofensor e, solidariamente, o partido político, no que couber. De outra parte, a proteção dos direitos autorais, consolidada na Lei $n^{\circ} 5.988$, de 14 de dezembro de 1973, tem como base o princípio de que o autor é titular de direitos morais e patrimoniais sobre a obra intelectual que produziu (art. 21). Todo um capítulo é dedicado à definição dos direitos morais do autor, passíveis de pretensão reparatória (arts. 25 a 28 ).

A noção do dano moral também se enquadra entre os direitos básicos do consumidor, objeto de legislação especial.

O Código de Defesa do Consumidor (Lei n ${ }^{\circ} 8.078$, de 11 de setembro de 1990) assegura "a efetiva prevenção e reparação de danos patrimoniais e morais", como expressão de garantia de direitos individuais, coletivos e difusos (art. $6^{\circ}, \mathrm{n}^{\circ} \mathrm{VI}$ ).

E, como forma peculiar de defesa do consumidor, prevê a lei a "proteção contra a publicidade enganosa e abusiva" (art. 6o, no IV) visando não somente a reprimir o dano econômico, como ainda, e especialmente, a resguardar a moralidade no ato de 
comércio, afastando a frustração que possa resultar, no espírito da clientela ludibriada, da compra de produto destituído da proclamada qualidade.

Por último, merece recordar que - como acima indicado - a atual Constituição coloca, como reflexo do direito à liberdade, a obrigação do Estado indenizar o condenado por erro judiciário, assim como ao que ficar preso além do tempo fixado na sentença (art. 5०, LXXV).

O Código de Processo Penal (Decreto-lei no 3.689, de 3 de outubro de 1941) antecipou, no capítulo da revisão criminal, o direito à indenização pelos prejuízos sofridos em caso de condenação ilícita. Responderá pela indenização, conforme o caso, a União ou o Estado, segundo a jurisdição da sentença revista (art. 630).

O prejuízo a ser compensado não será unicamente o dano material pela privação da liberdade, mas igualmente o dano moral que o vício de legalidade da condenação terá provocado quanto à reputação do réu ou aos reflexos da pena no meio familiar.

\section{IV}

A reparação do dano moral coloca em causa o delicado problema da quantificação do valor da indenização.

Se o dano material é, de regra, determinável por critério objetivo e certo, a avaliação do dano moral é, por sua natureza, subjetiva e aleatória.

A jurisprudência tem mesmo admitido que a determinação do valor leve em conta um fator sancionatório, de tal modo que o teor econômico desestimule, pelo efeito intimidativo, a reincidência em conduta ofensiva aos valores da personalidade (ver, a respeito, Renan Miguel Saad - o ato ilícito e responsabilidade civil do Estado 1994 - p. 100 a 105).

A imprensa noticiou, recentemente, dois casos na jurisprudência norte-americana, que exprimem a tendência a condenações de alto valor a título de danos punitivos (punitive damages).

Em um bar do Sul da Califórnia, ao tomar um café cappucino o usuário, deficiente físico, sofreu queimadura quando a alça da chícara descartável se desprendeu e a bebida quente caiu-lhe ao colo. Foi pleiteada indenização superior a um milhão de dólares, sendo 750 mil dólares sob o fundamento de que o incidente teria motivado "choque e prejuízo ao sistema nervoso da mãe do cliente, o que lhe causou e continua causando muita dor física e mental e sofrimento" (Gazeta Mercantil -7 de junho de 1994).

Recentemente, a companhia Mc Donald's foi condenada em US\$2,9 milhões por danos e prejuízos causados a uma anciã de 81 anos que, dirigindo automóvel, colocou entre as pernas copo com café quente e sofreu queimaduras de terceiro grau quando, ao abrir o tampo plástico, derramou nas pernas o café fervente adquirido numa das lojas da referida cadeia.

Declaradamente, a maior parte da condenação (US $\$ 2,7$ milhões) foi atribuída em razão do processo adotado no estabelecimento de servir o café a uma temperatura média de 80 graus centígrados, reputada excessiva, adotado o cálculo como punição à empresa (Gazeta Mercantil - 20-21 agosto de 1994). 
Estão em curso negociações, de iniciativa do juizo da ação, em busca de um acordo que, mediante indenização menor, induza a empresa a não recorrer da sentença (Gazeta Mercantil - 5 de setembro de 1994).

Em julgamento recente, a 6 Câmara Cível do Tribunal de Justiça do Estado do Rio de Janeiro condenou empresa editora de disco a indenizar autor brasileiro, pelo comprovado plágio de música de sua autoria, concedendo-lhe reparação de danos morais fixados em US\$ 32 mil (Gazeta Mercantil - 31 de agosto de 1994).

Em sentença proferida no Juízo da 27 a Vara Cível de São Paulo, e transitada em julgado, a CREDICARD foi condenada ao pagamento de indenização da ordem de US\$20 mil por danos morais e materiais, pela recusa, no exterior, de cartão de crédito erroneamente cancelado pela empresa (Gazeta Mercantil - 2 de setembro de 1994).

A Jurisprudência do Conselho de Estado francês por algum tempo repeliu a indenização por dano moral a pretexto de que a dor não é conversível em moeda (larmes ne se monnayent pas), afastando-se o pretium doloris como elemento de indenização (caso Quénot - 24 de março de 1916). Evoluiu, porém, o tribunal administrativo. Venceu outra linha interpretativa, para admitir o ressarcimento do que se convencionou chamar de "perturbação nas condições de existência da vítima ou de seus familiares" (casos Brusteau e Marx - 8 e 17 de dezembro de 1948). Finalmente, em decisão no caso Letisserand (24 de novembro de 1961 ) em definitivo aderiu o Conselho de Estado ao reconhecimento do dano moral como fato gerador de indenização, admitindo, como tal, a dor paterna pelo desaparecimento prematuro de seu filho (ver comentários de Marcel Waline - in Revue du Droit Public e de la Science Politique $-1962, n^{\circ} 2$, p. 330/333).

A responsabilidade civil do Estado tem sido, frequientemente, reconhecida por nossos tribunais, em casos de omissão no poder de polícia nos quais a inércia da autoridade administrativa é causa determinante, ou concorrente, na produção do dano.

IARA LEAL GASOS, em tese sobre o tema, trouxe à colação diversos casos da jurisprudência brasileira, nesse sentido (A omissão abusiva do poder de polícia 1994, p. 74 a 83 ).

A pesquisa ampla da jurisprudência judicial, entre nós, excede aos objetivos imediatos da presente comunicação.

Alinharemos, a seguir, apenas a título ilustrativo, alguns julgados que evidenciam a acolhida do dano moral como fundamento da responsabilidade do Poder Público.

O Tribunal de Justiça da Bahia declarou a responsabilidade do Estado pela reparação de erro judiciário, devendo a indenização cobrir os danos morais e materiais decorrentes de execução condenatória, em detrimento de réu inocente (acórdão na Apelação Cível no 322/82 - Revista de Direito Administrativo - vol. 157/258).

Em caso de morte de mulher, atingida por disparo de policial, no exercício de sua função, o Tribunal de Justiça do Estado do Rio de Janeiro afirmou a existência cumulativa do dano material, representado pela interrupção de serviços domésticos a cargo da vítima e de dano moral presumido à luz do vínculo com seus parentes ime-

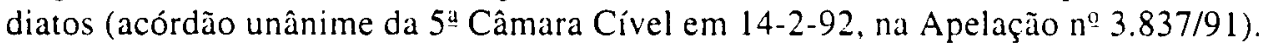

Em outro acórdão, o mesmo Tribunal, entendendo que o fato danoso "faz presumir ofendida a honra, ferindo a vítima na personalidade espiritual, nos afctos e sentimentos" condenou o réu à indenização cumulativa, aditandu, siğifícutivamente 
que "vinga na indenização por dano moral o propósito de se impor sanção exemplar" (acórdão unânime da 8a Câmara Cível, em 20-12-90, na Apelação Cível no 4.808/89).

Em acórdão de 29 de junho de 1984, na Apelação Cível no 85.689, o Tribunal Federal de Recursos entendeu cabível a reparação de dano moral, em virtude de morte causada por veículo militar, visto que "os pais da vítima de família pobre são presumidamente dependentes do filho solteiro pré-morto, pois todos contribuem para a economia doméstica" (Revista de Direito Administrativo - vol. 159/266).

Acolheu o Tribunal Federal de Recursos a responsabilidade da União pelo dano estético causado a uma mulher por lesão ocular provocada por lâmina de vidro que se desprendeu de edifício-sede de repartição federal (Acórdão na Apelação Cível no 73.865 - Revista de Direito Administrativo - vol. 153/183).

Mais expressiva, como evidência de dano moral, é a sentença condenatória da União no conhecido caso Herzog.

Preso político, a vítima foi encontrada morta por asfixia na cela a que estava recolhido em presídio militar, após sessões de tortura física e psicológica.

Alegou-se a prática de suicídio, mas a sentença de primeira instância, a par de ter como não comprovada a morte voluntária, afirmou a responsabilidade do Estado pela integridade física e moral do preso e filiou o óbito à coação moral a que estivera sujeito no curso da prisão arbitrária.

Aceitando a tese da responsabilidade objetiva do Estado, por culpa do serviço, a sentença declara a obrigação de indenizar por danos materiais e morais cumulativos (ver publicação da íntegra do processo - in Caso Herzog - Editora Salamandra 1978). Embora reformada em grau de recurso, por insuficiência de prova, a sentença oferece subsídio de relevo sobre o tema.

Casos de atropelamentos por veículos oficiais, gerando pretensões indenizatórias por dano moral à família, bem como os de responsabilidade por omissão de providências em desmoronamentos de encostas e a tolerância de construção em locais de risco, são espécies nas quais se tem afirmado não apenas o aspecto estritamente patrimonial como os reflexos que provocam em relação a respeitáveis interesses de ordem moral dos lesados, não raro postos ao desabrigo.

A responsabilidade vinculada à legislação de imprensa teve significativa aplicação com respeito ao noticiário inverídico que atribuiu a conhecido artista a contaminação por vírus da AIDS.

O Tribunal de Justiça do Estado do Rio de Janeiro condenou a empresa jornalística à indenização por dano moral, destacando, como um dos fundamentos da decisão que "nenhum homem médio poderia espancar os seus mais íntimos sentimentos de medo e frustração, de indignação e revolta, de dor e mágoa, diante da divulgação de seu nome associado a uma doença incurável, desafiadora dos progressos da ciência e que tantos desesperos tem causado à humanidade" (acórdão na Apelação Cível no 3.059/91 -- Revista de Direito Administrativo - vol. 185/197).

A reparação de danos morais tem merecido reconhecimento até mesmo em razão de ato legislativo. 
A lei inconstitucional não apenas se tornará nenhuma uma vez declarado o vício que nulifica seus efeitos.

Como afirmou o Supremo Tribunal Federal, em acórdão de 19 de julho de 1948, "o Estado responde civilmente por dano causado em virtude de ato praticado com fundamento em lei declarada inconstitucional". Trata-se de empresa de ônibus da qual se exigira imposto indevido, conduzindo à suspensão do tráfego (Revista de Direito Administrativo - vol. 20/42).

Em outro feito, definiu a Suprema Corte que "uma vez praticado pelo poder público um ato prejudicial que se baseou em lei que não é lei, responde ele por suas consequiências" (acórdão de 15 de maio de 1957).

O voto do Relator, Ministro Cândido Mota Filho, enfatizou o princípio de que:

"O Estado responde civilmente pelos danos causados por lei declarada inconstitucional, pois ele não pode, na verdade, pelo arbítrio legislativo, abalar as garantias dos contratos regularmente feitos" (Revista Trimestral de Jurisprudência - 2/121122).

Não é outra a jurisprudência atual no Pretório Excelso como documenta o despacho do Ministro Relator no Recurso Extraordinário no 169.81 (Revista de Direito Administrativo - vol. 194/271).

Se, nessas hipóteses, foi admitida a indenização por danos materiais, o princípio da responsabilidade do Estado por leis inconstitucionais, que neles se afirma, leva a conclusão necessária de que de igual premissa resultará a reparação de danos morais que possam provir dos efeitos de ato legislativo que afinal tenha proclamada a eiva de inconstitucionalidade.

\section{VII}

A conclusão que se impõe, em suma, é a de que o Estado responderá objetivamente pelos danos materiais ou morais, comprovadamente oriundo de atos de qualquer dos três Poderes, obrigando-se a reparar os prejuízos causados, a serem quantificados em grau de execução.

Não há, para o Poder Público privilégios ou prerrogativas que possam eximi-lo do dever, que a todos se impõe, de preservação da integridade de bens ou direitos protegidos pela segurança da ordem jurídica. 